\title{
Dementia Early Stage Cognitive Aids New Trial (DESCANT) of memory aids and guidance for people with dementia: randomised controlled trial
}

Paul Clarkson* (0000-0002-0778-312X), Rosa Pitts, Saiful Islam, Julie Peconi, Ian Russell, Greg Fegan, Rebecca Beresford, Charlotte Entwistle, Vincent Gillan, Martin Orrell, David Challis, Helen Chester, Jane Hughes, Narinder Kapur, Brenda Roe, Baber Malik, Catherine Robinson

\section{Author addresses:}

Paul Clarkson Senior Lecturer in Social Care, Social Care and Society, Division of Population Health, Health Services Research and Primary Care, University of Manchester, M13 9PL, UK email: paul.clarkson@manchester.ac.uk

Rosa Pitts Research Assistant Social Care and Society, Division of Population Health, Health Services Research and Primary Care, University of Manchester, M13 9PL, UK email: r.pitts1@lancaster.ac.uk

Saiful Islam Statistician Swansea Trials Unit, Swansea University Medical School, Swansea, SA2 8PP, Wales, UK email: $\underline{\text { m.s.islam@swansea.ac.uk }}$

Julie Peconi Assistant Trial Manager, Swansea Trials Unit, Swansea University Medical School, Swansea, SA2 8PP, Wales, UK email: J.Peconi@swansea.ac.uk

Ian Russell Statistician Swansea University Medical School, Swansea, SA2 8PP, Wales, UK email: i.t.russell@swansea.ac.uk

Greg Fegan Professor of Clinical Trials Swansea Trials Unit, Swansea University Medical School, Swansea, SA2 8PP, Wales, UK email: g.w.fegan@swansea.ac.uk

Rebecca Beresford Research Assistant Social Care and Society, Division of Population Health, Health Services Research and Primary Care, University of Manchester, M13 9PL, UK email: rebecca.beresford@manchester.ac.uk

Charlotte Entwistle Research Assistant Social Care and Society, Division of Population Health, Health Services Research and Primary Care, University of Manchester, M13 9PL, UK email: c.entwistle1@lancaster.ac.uk

Vincent Gillan Research Assistant Social Care and Society, Division of Population Health, Health Services Research and Primary Care, University of Manchester, M13 9PL, UK email: vinny-gillan@live.co.uk

Martin Orrell Professor of Psychiatry Institute of Mental Health, University of Nottingham, NG7 2TU, UK email: M.Orrell@nottingham.ac.uk

David Challis, Professor of Social Care Institute of Mental Health, University of Nottingham, NG7 2TU, UK email: David.Challis@nottingham.ac.uk

Helen Chester Senior Research Fellow Institute of Mental Health, University of Nottingham, NG7 2TU, UK email: Helen.Chester@nottingham.ac.uk

Jane Hughes Senior Research Fellow Institute of Mental Health, University of Nottingham, NG7 2TU, UK email: Jane.Hughes@nottingham.ac.uk

Narinder Kapur Visiting Professor of Neuropsychology University College London, London, WC1E 6BT, UK email: narinder.kapur1@gmail.com 
Brenda Roe Emerita Professor of Health, Faculty of Health, Medicine and Social Care, Edge Hill University, Ormskirk, L39 4QP, UK email: bhroe@aol.com

Baber Malik Research Associate/Honorary Fellow Social Care and Society, Division of Population Health, Health Services Research and Primary Care, University of Manchester, M13 9PL, UK email: baber.malik@manchester.ac.uk

Catherine Robinson Professor of Social Care Research Social Care and Society, Division of Population Health, Health Services Research and Primary Care, University of Manchester, M13 9PL, UK email: catherine.robinson@manchester.ac.uk

\section{* Corresponding author:}

Paul Clarkson Senior Lecturer in Social Care, Social Care and Society, Division of Population Health, Health Services Research and Primary Care, University of Manchester, M13 9PL, UK email: paul.clarkson@manchester.ac.uk

\section{Contributorship}

PC (chief investigator, 08/04/2019 to 31/03/20): conceived and designed the study and had overall responsibility for study delivery and is the joint guarantor. RP was responsible for trial logistics and management, and led on writing and reviewing of the manuscript. SI did the statistical analysis. JP had lead responsibility for trial logistics and management, and was responsible for writing and reviewing of the manuscript. IR was a grant holder and was responsible for trial design and statistical analysis and for writing and reviewing of the manuscript. GF had lead responsibility for trial management and was responsible for writing and reviewing of the manuscript. RB was responsible for trial logistics and management and writing and reviewing of the manuscript. CE was responsible for trial logistics and management. VG was responsible for trial logistics and management. MO was a grant holder, conceived and designed the study, and developed the intervention. JH was a grant holder, helped design the study, led on the development of the training manual and was involved in trial management. $\mathrm{HC}$ was responsible for trial management and recruitment lead (until 30/05/2019), responsible for training and quality assurance and developed and helped implement the intervention. DC (chief investigator, 01/07/2015 to 07/04/2019): conceived and designed the study and had responsibility for study delivery. NK was a grant holder, and developed the intervention and trained DSPs in its use. BR was a grant holder and led on PPCRG activities with PC. BM was responsible for trial management (from 30/05/2019 to 31/03/2020). CR (co-chief investigator, 08/04/2019 to 31/03/2020): had responsibility for study delivery and for reviewing of the manuscript. She is the joint guarantor. All authors have contributed to drafting the manuscript and approving the final version. The corresponding author attests that all listed authors meet authorship criteria and that no others meeting the criteria have been omitted. 


\section{Funding statement}

This trial was funded by the National Institute for Health Research (NIHR Programme Grants for Applied Research, Grant Number DTC-RP-PG-0311-12003) and received additional support from the NIHR Local Clinical Research Networks in England and Wales. NIHR funded the study. It developed a commissioning brief but had no role in the study design, data acquisition, analysis, or manuscript preparation. The sponsor (University of Manchester) had no role in the funding, study design, in the collection, analysis, and interpretation of data, in the writing of the report and in the decision to submit the article for publication. The views expressed are those of the authors and are not an official view of the institutions or funders. All authors had full access to the data (including statistical reports and tables) in the study and take responsibility for the integrity of the data and the accuracy of the data analysis.

\section{Competing of interests}

All authors have completed the ICMJE uniform disclosure form at www.icmje.org/coi_disclosure.pdf and declare: all authors had financial support from the National Institute for Health Research for the submitted work; no financial relationships with any organisations that might have an interest in the submitted work in the previous three years; no other relationships or activities that could appear to have influenced the submitted work.

\section{Ethical approval}

This study was approved by national ethics review committee (REC No 16/NW/0389; 13/05/16), Health Research Authority (HRA) and research governance in each organisation. All participants or consultees gave informed consent before taking part.

\section{Copyright}

The Corresponding Author has the right to grant on behalf of all authors and does grant on behalf of all authors, an exclusive licence (or non-exclusive for government employees) on a worldwide basis to the BMJ Publishing Group Ltd to permit this article (if accepted) to be published in BMJ editions and any other BMJPGL products and sublicences such use and exploit all subsidiary rights, as set out in our licence.

\section{Transparency}

The lead author (PC) affirms that the manuscript is an honest, accurate, and transparent account of the study being reported; that no important aspects of the study have been omitted; and that any discrepancies from the study as planned (and, if relevant, registered) have been explained.

\section{Dissemination to study participants and patient organisations}

The findings from this trial will be dissemination to study participants who elected to receive information about the study and will be disseminated through the Patient and Public Involvement carers' charity, TIDE (Together in Dementia Everyday).

\section{Author Licence}

I, the Submitting Author has the right to grant and does grant on behalf of all authors of the Work (as defined in the author licence), an exclusive licence and/or a non-exclusive licence for contributions from authors who are: i) UK Crown employees; ii) where BMJ has agreed a 
CC-BY licence shall apply, and/or iii) in accordance with the terms applicable for US Federal Government officers or employees acting as part of their official duties; on a worldwide, perpetual, irrevocable, royalty-free basis to BMJ Publishing Group Ltd ("BMJ") its licensees. The Submitting Author accepts and understands that any supply made under these terms is made by BMJ to the Submitting Author unless you are acting as an employee on behalf of your employer or a postgraduate student of an affiliated institution which is paying any applicable article publishing charge ("APC") for Open Access articles. Where the Submitting Author wishes to make the Work available on an Open Access basis (and intends to pay the relevant APC), the terms of reuse of such Open Access shall be governed by a Creative Commons licence - details of these licences and which licence will apply to this Work are set out in our licence referred to above.

\section{Acknowledgements}

We thank all participants and their carers for agreeing to take part in the study. We would like to thank the following for their important contributions: Programme steering committee (independent members): Ken Wilson, Gail Mountain, Sue Watts, Eileen Symonds, Sabine Landau, and David Britt. Data monitoring and ethics committee: Peter Crome (Chair), Gill Manthorpe, Linda Clare, Zoe Hoare, Anthony Hodgson. Patient and Public Involvement Reference Group: Brenda Roe, Jean Tottie, Anthony Hodgson, Julie Dickinson, Phil Dickinson, Jennifer Lord, David Britt, Cathy Clarke, Graham Gavin, Eileen Gilbert, Dave Gilbert, Dawn Williams, Susan Healey, Joyce Dunne, Jacqui Walker, Cecilia Toole. We thank other members of the DESCANT Trial Team at the University of Manchester, Linda Davies and Sue Davies and interviewers, research nurses and managers in each of the NHS sites undertaking the trial: Carol Harper, Carol Ainsworth, Simon Kaye, Linda Booth, Kim Bennett, Brenda Pimlott, Reagan Blyth, Mrudula Davé, Kim Bennett, Jessica Whiston, Ritchard Ledgerd, Jane Burgess, Krisha Hirani, Jemima Hassan, Sheetal Dandgey, Pat Mottram, Theresa Whittingham, Caroline Mogan, Helen Leyland, Dianne Jones, Willemijn Spoor, Annette.Haddon-Silver, Cathryn Hart, Gavin Dawson, Saba Alam, Kathryn Gilgallon, Emma Anderson, Daniel Kelleher, Pretha Koshy, Lauren Sugden, Sarah Trufhitt, Jo Waring, Antony Bayer, Charlotte Colbeck, Alex Carey, Alison Stubbs, Gina Nelson, Rebecca Davies, Dan Pulford, Polly Bidwell, Shani McCoy, Leena Reddy, Penny Lane, Janine Smith, Viraj Rahul, Liz Dalton.

\section{Data sharing}

The relevant anonymised patient level data, full dataset, technical appendix, and statistical code are available on reasonable request from the corresponding author. Consent for data sharing was not obtained but the presented data are anonymised and risk of identification is low. 


\begin{abstract}
BACKGROUND

Common memory aids for people with dementia at home are recommended. However, rigorous evaluation is lacking, particularly what guidance or support is valued.
\end{abstract}

\title{
OBJECTIVE
}

To investigate effects of memory aids and guidance by Dementia Support Practitioners (DSPs) for people in early stage dementia through a pragmatic, randomised controlled trial.

\section{METHODS}

Of 469 people with mild to moderate dementia and their informal carers, 468 were randomised to a DSP with memory aids or to usual care plus existing dementia guide. Allocation was stratified by: Trust/Health Board; time since first attendance at memory service; gender; age; and living with primary carer or not. Primary outcome was Bristol Activities of Daily Living Scale (BADLS) score at 3 and 6 months (primary end-point). Secondary outcomes for people with dementia: quality of life (CASP-19; DEMQOL); cognition and functioning (Clinical Dementia Rating Scale; SMMSE); capability (ICECAP-O); social networks (LSNS-R); and instrumental daily living activities (R-IDDD). Secondary outcomes for carers: psychological health (GHQ-12); sense of competence (SSCQ).

\section{RESULTS}

DSPs were successfully trained, compliance was good and welcomed by participants. Mean 6 months BADLS score increased to 14.6 (SD 10.4) in intervention and 12.6 (SD 8.1) in comparator, indicative of greater dependence in the activities of daily living. Adjusted between group difference was 0.38 (95\% confidence interval -0.89 to $1.65, \mathrm{P}=0.56)$. Though this suggests greater dependency in the intervention group the difference was not significant. No differences were found in secondary outcomes.

\section{CONCLUSIONS}

This intervention did not maintain independence in the activities of daily living with no improvement in other outcomes for people with dementia or carers.

\section{TRIAL REGISTRATION}

Current Controlled Trials ISRCTN12591717. 


\section{INTRODUCTION}

Dementia affects over 47 million people worldwide [1], with 850,000 people with dementia in the UK at any one time [2]. Numbers are predicted to increase, creating a challenge for health and care services to meet the needs of individuals living with the condition and their families [3]. Many people with dementia find it difficult to manage their day to day problems. Interventions to help them and their families manage these problems and difficulties can help to maintain functioning, and so independence from carer help, thus improving quality of life. To address this, the Lancet Commission on Dementia [4] recommended that interventions should be multi-component, individualised to need, support carers in their coping skills and modify the environment around the person with dementia. Provision of memory aids, for those diagnosed with early-stage dementia, aiming to assist with daily living activities by sustaining cognitive and functional abilities [5, 6] and reducing carer burden [7] have been explored. The use of these common, low-technology, aids, like calendars, clocks, whiteboards with electric timers, and "post-it" note dispensers, is widely recommended in clinical practice and by support organisations [8]; many are used by people with dementia at home, often with support from their family carers. However, rigorous effectiveness evaluation is lacking, particularly of what guidance for using aids is valued, although people with dementia report a preference for such advice to be provided at home by a trained worker [9]. A Cochrane review [10] identified several studies reporting the usefulness of such memory aids or associated training, but they were small or low quality, with only two trials identified. One trial [11] evaluated improvement in medication adherence from using an electronic pill dispenser, but although participants had memory impairment they had no validated dementia diagnosis. The ATTILA RCT [12], evaluated whether assistive technology and telecare assessments and interventions extend the time people with dementia may continue to live independently at home. However, the interventions were not directed towards assistance with memory problems but rather safety concerns (for example provision of pendant alarms). This review therefore highlighted the need for a larger and more dedicated study, building on evidence from small-scale trials and other studies [13-17].

The rationale for these aids is that they can help people with dementia overcome some of the effects of their memory problems so promoting achievement of daily living activities for longer. In a context where memory is progressively deteriorating, the effectiveness of such memory aids would not be judged by improvements in cognition per se, but by the extent to which people with dementia may act more independently to attain their daily goals, for example keeping appointments and performing activities independently. This is the domain in which the effects of such aids may be judged as successful or not - the proximal, or targeted outcome that such interventions are designed to impact upon following completion. There may be further distal outcomes from use of such aids; the person may be less agitated or confused, and may experience a better quality of life; and their informal carers may experience less burden $[18,19]$.

The Dementia Early Stage Cognitive Aids New Trial (DESCANT), a multi-site, pragmatic randomised trial, tested the effectiveness of this approach on relevant outcomes for people with dementia and their carers. We implemented and evaluated the effectiveness of guidance by Dementia Support Practitioners (DSPs) to support people with early-stage dementia and their carers in using memory aids at home, relative to treatment as usual (TAU). We designed the intervention to be relatively inexpensive, realistic and scalable [20] for use within the UK NHS or by third-sector organisations. 


\section{METHODS}

\section{Study design}

This trial was preceded by a feasibility study and internal pilot. Randomisation allocation was in equal proportions between intervention and comparator groups. We recruited people with mild to moderate dementia with an identified primary carer - from memory services within 10 Health Trusts/Boards across England and Wales. Trained DSPs delivered the interventions in participants' homes.

Trained interviewers assessed the capacity to consent of potential participants according to the principles of the Mental Capacity Act (2005). We asked those judged to have capacity for their written informed consent. For those judged to lack capacity, we asked their primary carer or a personal consultee about their whether the person would have consented and asked that person to provide written consent on their behalf.

Carers gave written informed consent to provide data about the person with dementia. We checked their agreement to continue participation at each visit. We also undertook interviews with carers to investigate their own outcomes, for which they provided separate written informed consent.

\section{Participants}

Eligibility criteria for people with dementia were; diagnosed dementia of mild to moderate severity; aged 50 years or more; under the care of a trial memory clinic; within one year of their first attendance for dementia; physically (judged from medical records) and clinically (judged by a responsible clinician) able to engage with the intervention, for instance able to hold, view and use the memory aids and be sufficiently able to interact with the DSP; living in their own home or sharing with a relative; and having an identified carer, defined as the primary person who feels responsible and supports them.

\section{Study treatments}

Our trial protocol describes the intervention and rationale [21]. The 4-week intervention aimed to improve the abilities, functioning and independence of people with early-stage dementia and their carers, by providing a range of memory aids, and training and support in their use. Dementia Support Practitioners (DSPs) delivered the intervention using a manual (https://sites.manchester.ac.uk/home-support-dementia/) to guide each of the four sessions, with worksheets to facilitate and record delivery ('Intervention record'). The aim was to deliver the first session face-to-face at home to participant pairs within two weeks of randomisation. During this session DSPs collected information about memory problems, current use of memory aids, and what goals participants would like to achieve by participating, using standardised and study specific worksheets [22]. DSPs provided an appropriate pack of memory aids and support at the first session. They used core memory aids: whiteboard; clock showing day and date; post-it notes; pen and notepad; and calendar. These were selected as they are readily available, were simple to install, and are relatively inexpensive. DSPs also had the flexibility to purchase more items within a budget of $£ 150$ per participant to tailor their intervention to individual goals. Additionally, they could also provide support with memory aids already in use within the home. Two telephone follow-up support sessions and a final session face to face at home with participants and their carers were undertaken by DSPs. Whilst the first and fourth sessions were a core part of the intervention, intermediate support sessions - telephone or face-to-face to deliver or adjust a memory aid-were optional. A reflection of the fact that this was a personalised intervention, throughout there was flexibility for participants, people with dementia or carers, to meet the DSP jointly or separately if they wished, and it was recognised that the extent of participation in each session could vary depending on the preferences of the person with dementia and their carer [22]. 
All participants received usual care from memory clinics, in accordance with clinical guidance. This comprised help from clinic staff, post-diagnostic counselling and advice, and specialist follow up as appropriate.

\section{Data collection}

We trained clinical staff in participating sites. They completed a screening tool to check participant eligibility, gave a participant information sheet to eligible participants, and sought oral consent to refer them to the DESCANT team. We collected baseline data from outcome questionnaires before randomisation and followed all participants up three and six months after randomisation. The research team checked the quality of these data.

\section{Outcomes for people with dementia}

The primary outcome at 6 months was the carer-rated Bristol Activities of Daily Living Scale (BADLS) [23], representing independence in the activities of daily living; scored 0 to 60 with higher scores showing worse impairment. Secondary outcomes at 3 and 6 months after randomisation were: Control, Autonomy, Self-realisation and Pleasure 19-item (CASP19) [24], scored 0 to 57 with higher scores showing better quality of life; Clinical Dementia Rating scale (CDR) [25], scored 0-3 with higher scores showing worse cognitive and behavioural functioning; Dementia Quality of Life (DEMQOL [26], scored 28 to 112 with higher scores showing better quality of life; Investigating Choice Experiments for the Capability of Older people (ICECAP-O) [27], scores between 0 (no capability) to 1 (full capability); Lubben Social Network Scale - Revised (LSNS-R) [28], scored 0 to 60, with higher scores showing more social engagement; Revised Interview for Deterioration in Daily Living Activities in Dementia (RIDDD [29], with Initiative scoring between 0 and 60, Performance scoring between 0 and 76 and higher scores showing greater impairment; and the Standardised Mini-Mental State Examination (S-MMSE) [30], scored between 0 and 30 with lower scores showing worse cognitive impairment. To estimate use of health and social care resources we completed the Client Services Receipt Inventory [31] and Resource Utilisation in Dementia questionnaire [32]. The interviews took about one and a half hours [33].

\section{Outcomes for carers}

Secondary outcomes for carers were the General Health Questionnaire (GHQ-12) [34], scoring between 0 and 36 with higher scores showing worse health and the Short Sense of Competence Questionnaire (SSCQ) [35], scoring from 7 to 35 with higher scores showing greater competence.

\section{Randomisation and masking}

Trial managers coordinated recruitment and forwarded participants' details to the trials unit's email-based randomisation service. After baseline interviews, the unmasked trial data manager oversaw randomisation, which allocated participants in equal proportions between intervention and comparator groups, stratified by: Trust or Health Board (one of 10); time since first attendance at memory clinic (more or less than 90 days); gender (male or female); age (more or less than 75 years); and living with primary carer or not. Allocation between groups used dynamic software to randomise participants in real time, thus preventing subversion while ensuring (stochastic) balance between groups [36]. Participants then received a letter specifying their allocated group and reminding them what this entailed. Participants in the comparator group received a general guide to dementia [8]. Participants in the intervention group received invitations to arrange initial visits by the DSP within 2 weeks of randomisation.

Masking participants, carers, or DSPs was not possible. Researchers conducting baseline and follow-up interviews were masked to treatment condition and participants were asked not to disclose the group they were allocated to. In this way, interviewers were kept masked as much as possible, although we also asked them to indicate what group they believed the participant had been allocated to at the end of each follow-up interview. 


\section{Sample size}

We calculated that an analysable sample of 360 (180 in each group) across participating sites would yield $80 \%$ power to detect an effect size (standardised mean difference) of 0.30 on BADLS, using a two-sided significance level of $5 \%$. To allow for $25 \%$ attrition (estimated from previous studies [37]) between baseline and final interviews, we aimed to randomise 480 pairs of people with mild to moderate dementia and their carers.

\section{Statistical Analysis}

Analysis followed a statistical analysis plan approved by our Data Monitoring and Ethics Committee (DMEC) before data were accessed. We analysed data on all participants by treatment allocated. Analyses were done in Stata V.16. We present descriptive statistics, by group, for baseline characteristics of participants randomised and in the primary analysis. To characterise the effect of the intervention over time, we fitted multi-level mixed-effect models, as these take better account of missing data, especially if missing at random, and explicitly account for correlations between repeated measurements within each participant [38]. Analyses by treatment allocated estimated the effect of the intervention on participants by adjusting for baseline differences in the measure under analysis, participant characteristics (viz. Trust/Health Board, age, gender and ethnicity), time since first attendance at memory clinic or equivalent, whether living with primary carer or not, and the time to follow up. We followed this plan both in primary analysis of BADLS and secondary analyses of all other outcomes.

We excluded participants without any follow-up data from the main analyses. We followed published rules for imputing missing data for individual outcome measures. To investigate the potential effects of missing data on the primary outcome, we performed a multiple imputation with Markov Chain Monte Carlo (MCMC) procedures. This, the most common parametric approach for multiple imputation, assumes that all the variables in the imputation model have a joint multivariate normal distribution. We undertook sensitivity analysis comparing estimates with and without imputation.

\section{Study monitoring}

A Trial Management Group (TMG) monitored compliance with the study protocol, operating procedures and liaised with Trusts/Boards to recruit participants. The TMG oversaw and resolved operational issues, and reported to the DMEC, the Programme Steering Committee and the funder.

To ensure the intervention and research methods worked in practice, we completed an internal feasibility study and pilot with 40 participants recruited from the two initial host Trusts in equal numbers, in August 2017. We adapted the Acceptance Checklist for Clinical Effectiveness Pilot Trials (ACCEPT) criteria [39] to assess whether the intervention and trial protocol worked in practice, and the DMEC accepted these criteria. The decision from the pilot was that the design and methods were feasible and appropriate and that the intervention training and procedures were acceptable, to DSPs and participants. DSPs considered the available budget to be feasible to fund necessary items. Despite their low cost they found the aids to potentially permit individualised responses to identified needs. Participants valued the strategies and advice from DSPs in tandem with the provision of aids. Participants provided positive feedback to DSPs about the memory aids, particularly the orientation clock, whiteboards and calendars. People with dementia reported reduced reliance on their carer and carers the opportunity to discuss dementia and its impact [22]. The only adjustment suggested by the pilot was to reduce the length of follow up from the initially planned 12 months to 6 months for the main study. This enabled us to meet recruitment targets and tackle the more realistic goal of improving BADLS scores over 6 months. Thus, we included the pilot data, adjusted to reflect this change, in the main analyses. The University of Manchester as Sponsor approved this modification and we 
communicated this to the National Research Ethics Service who approved the original protocol, sites and participants.

The DMEC could halt the trial for safety or ethical concerns. Only the DMEC had access, through the trial data manager, to un-blinded data before the trial ended in November 2019 and they approved the blinded primary analysis.

\section{Patient and carer involvement}

We involved people with dementia and their carers through a Public, Patient and Carer Reference Group (PPCRG), in North West England and a Lay Advisory Panel across the country, established through Together in Dementia Everyday (TIDE), a national charity advocating on behalf of carers of people with dementia. The PPCRG helped specify research questions, select outcome domains and design the intervention, including guidance given to the comparator group. The PPCRG also advised on data collection procedures, patient facing materials and on strategies to boost recruitment. Carers of people with dementia were formal members of the trial DMEC and Programme Steering Committee.

\section{RESULTS}

\section{Trial progression and recruitment}

We recruited participants incrementally over 3 years, with sites added from the support to recruitment provided by the infrastructure of the funder, the National Institute for Health Research in England. Figure 1 shows that between 25/11/16 (first participant enrolled on 6/12/16) and 25/11/19 (when data were locked for analysis), we screened 4426 people, found 1680 potentially eligible and recruited 470; as one participant missed the home visit and thus informed consent and another withdrew before randomisation, we randomised 468 -234 to the intervention and 234 to usual care. Four (2\%) participants died in the intervention group and $6(3 \%)$ in the comparator. The mean (SD) duration of intervention visits was 94 minutes (29) for the first visit, 17 (11) for first follow up, 17 (16) for second follow up, and 55 (25) for the final review [22]. The intervention followed at a mean (SD) of 15 (11) days after randomisation. The mean (SD) number of days between first and last sessions was 26 (9). In total 121 participants (58 intervention and 63 comparator) withdrew: 75 actively withdrew (31 intervention and 44 comparators); 31 were lost to follow up (19 intervention and 12 comparators); one participant withdrew following a Serious Adverse Event unrelated to the intervention; and one for another reason (both intervention). Ten participants died (four intervention and six comparators), and reasons were missing for three participants (two in the intervention arm).

\section{Sample}

The 468 randomised participants was slightly fewer than the 480 estimated as needed to achieve our analysis target of 360 , to allow for attrition characteristic of recruitment in this vulnerable population. Attrition at 6 months was slightly higher than expected (26\% rather than $25 \%$ ), so the number of participants for primary analysis, with data at baseline and 6 months, was 347 , also slightly lower than target. Baseline characteristics of the randomised and analysed samples were well-balanced (Table 1). The average age of those with dementia was around 80 years, with slightly more females. At referral, 376 people $(80 \%)$ with dementia were able to provide informed consent; the remaining $92(20 \%)$ needed a consultee. Table 1 shows baseline characteristics of randomised and analysed participants.

\section{Intervention}

DSPs in each of the 10 Trusts/Health Boards delivered the intervention to people with dementia and their carers. A sample of 126 intervention records [22] showed good engagement with almost all participants (98\%) fully completing the sessions, delivered as planned with packages individually tailored to participants' preferences. The mean interval between randomisation and the first home visit, the duration of visits, and the total duration 
of the intervention, were consistent with study protocol. Variations in delivery typically reflected participants' goals and preferences (e.g. time of day, availability of a carer) and DSP availability. Misplacement of items and orientation to date and time were common areas of need. Memory aids frequently supplied or supported included orientation clocks, whiteboards, calendars and notebooks as well as bespoke items. The intervention was acceptable, with little negative feedback. Unforeseen benefits included the recognition of undiagnosed memory issues in a family member and the use of memory aids by other family members to coordinate care [22].

\section{Resource use}

At baseline health and social care resource use differed between arms: more people with dementia in the intervention group had been inpatients on general medical wards (online supplemental Table A1). Some participants already had memory aids at home, notably clocks or medication reminders, but without guidance from a DSP; this existing use of aids did not differ between groups. At six months, more intervention participants had received visits from a social worker, dementia support worker or health visitor; or been admitted to general medical wards. More participants in the usual care group had received aids, adaptations or equipment at follow up. We report cost-effectiveness of the intervention elsewhere [40].

\section{Serious Adverse Events}

There were 43 Serious Adverse Events (SAEs) in 42 participants (24 intervention and 18 comparators). One comparator experienced two SAEs, both falls. People with dementia experienced 36 of these SAEs. No SAE was definitely, probably or possibly related to the intervention. Eight SAEs resulted in death (4 in intervention arm, 4 in comparator); three were life threatening (1 intervention, 2 comparator); two caused persistent or significant disability or incapacity (both intervention); one comparator suffered another medically important condition; and 29 were hospitalised (17 intervention, 12 comparator).

\section{Outcomes}

Table 2 shows the main treatment effect estimates for the primary outcome. The intervention group began with higher unadjusted BADLS scores (showing more dependency), which stayed constant at 3 months, but showed a marked increase to significantly higher dependency than the comparator group at 6 months. This significance was due in part to higher BADLS scores in comparators who were lost to follow-up or died between baseline and 6 months.

The multi-level mixed-effects models showed no significant differences between arms over time (Table 3 and Figure 2) in BADLS, the primary outcome. Outcomes in both groups reflected increasing dependency over time in activities of daily living. BADLS scores, showed a mean difference of only 0.38 at 6 months, slightly but not significantly favouring the comparator group ( $95 \%$ confidence interval from -0.89 to $1.65, p=0.56$ ). There were no significant differences between groups for all other patient-reported and carer reported outcomes (Table 4 presents summary data; Tables A2-A11 present full data for each).

Sensitivity analyses for the primary outcome, BADLS, accounting for missing data showed no differences in outcome estimates with and without imputation (appendix, Table A12; Figure A1).

At 6 months, interviewers indicated they knew treatment assignment in 33/234 cases (14\%) in the usual care arm and 82/234 (35\%) in the intervention arm (overall $25 \%$ ). Including masking status in covariate adjustment did not alter the treatment effect.

\section{DISCUSSION}


Our four-week programme, in which DSPs added to usual care by offering guidance in the use of memory aids at home, did not improve independence in the activities of daily living for people with mild to moderate dementia. We implemented the intervention as planned, and people with dementia and their carers welcomed it. But that did not translate into improvements in independence in activities of daily living, quality of life, or in carers' outcomes.

\section{Comparison with previous studies}

These results are less positive than some other studies [41, 42], but those studies are smaller and in single centres. Furthermore, those interventions were not as well designed and included little dedicated training. Some previous studies investigated provision of memory aids and training and concluded that these helped with everyday memory. One trial of a memory aids service [43] compared a three-session six-week clinic programme with waiting list controls for people with neurological conditions. This benefited participants' everyday memory goals if they had a non-progressive condition; but did not measure activities of daily living. There were no benefits for those with progressive conditions, like dementia. That study concluded that more than three training sessions were needed for those with progressive memory problems. Another trial [41] reported training in using a notebook/calendar system for participants with mild cognitive impairment and found beneficial effects on activities of daily living. However, this recruited only 40 participants and excluded participants with dementia. A trial of cognitive rehabilitation for people with earlystage Alzheimer disease [42], including practical aids and strategies to assist memory, found improved goal performance and satisfaction, but randomised only 69 participants.

\section{Strengths and limitations}

We improved upon previous studies by including systematic training and record-keeping, and an extended number of sessions in participants' homes - a familiar environment most likely to yield benefit. We delivered the intervention as planned, with good compliance by participants and carers. Compared with other trials we recruited a much larger sample and covered a greater geographical spread. Our analysis of both observed and fully imputed data, taking account of missing data, yielded similar estimates of treatment effects on activities of daily living.

Though we could not mask participants and carers to treatment allocation, masking was neither feasible nor desirable. Recruiting enough people with dementia living at home is challenging for all such trials. Though our sample was slightly smaller than target, and our analysis slightly underpowered, we found no hint of benefit.

\section{Interpretation}

Our intervention was implemented successfully [22], with high compliance and delivery as planned. Following several small studies, we aimed to improve independence in activities of daily living by using DSPs to deliver memory aids to participants' homes, and guide their use. Our pre-specified effect size, used in our sample size calculation, corresponded to a 3.5 minimum clinically important difference on BADLS, with a standard deviation of 8.7 [44] However, we found an adjusted average effect of only 0.38 , with dependency in the activities of daily living increasing over time, consistent with published evidence [45]. Any slowing of that dependency is a valuable consequence of care with tertiary prevention a legitimate aim [4]. But the intervention did not achieve that aim. It may be that this kind of practical intervention may be useful much earlier in the course of dementia in promoting independence, even before diagnosis when abilities have not deteriorated to the same extent. However, assistance like this cannot be accessed earlier in existing service systems (at least in the UK) as diagnosis is the gateway to receiving such formal, tailored support. However, it could also be that the 4-week duration of this intervention was insufficient to realise its potential effects. 


\section{Recommendations}

A dedicated practitioner to guide and advise on the use of memory aids cannot be recommended as a care option to maintain independence in activities of daily living in people with dementia. In future, similar trials should investigate other outcomes valued by people with dementia, for example engagement and other, more subtle effects, such as increased confidence, enhanced relationships, feeling valued and respected, not yet measured in trials [46]. The effectiveness of offering other types of guidance needs investigation with such outcome measures. However, this intervention was not an effective way to manage daily living activities, or our other outcomes, for people with mild to moderate dementia or their carers.

\section{CONCLUSION}

A four-week programme of advice, guidance and support in using memory aids, did not increase independence in activities of daily living in people with mild to moderate dementia. Although well received and providing reassurance in other areas, such as enhanced information for carers and advice as to unmet needs, it did not improve the outcomes studied.

\section{References}

1- World Health Organization. The epidemiology and impact of dementia. Current state and future trends. World Health Organisation, 2015.

2- Prince M, Knapp M, Guerchet M, et al. Dementia UK: Update. Alzheimer's Society, 2014.

3- Department of Health. Prime Minister's challenge on dementia 2020. Department of Health, 2020.

4- Livingston G, Sommerlad A, Orgeta V, et al. Dementia prevention, intervention, and care. Lancet 2017; 390(10113): 2673-734.

5- Clare L, Kudlicka A, Oyebode JR, et al. Individual goal-oriented cognitive rehabilitation to improve everyday functioning for people with early-stage dementia: A multicentre randomised controlled trial (the GREAT trial). Int J Geriatr Psychiatry 2019; 34:709-21.

6- Gillespie A, Best C, O'Neill B. Cognitive function and assistive technology for cognition: A systematic review. J Int Neuropsychol Soc 2012; 18:1-9.

7- McHugh JE, Wherton JP, Prendergast D, Lawlor BA. Identifying opportunities for supporting caregivers of persons with dementia through information and communication technology. Gerontechnology 2012; 10:220-30.

8- Alzheimer's Society. The memory handbook: a practical guide to living with memory problems. Alzheimer's Society, 2014; https://www.alzheimers.org.uk/sites/default/files/202003/The\%20memory\%20handbook\%201540.pdf

9- Chester H, Clarkson $\mathrm{P}$, Davies L, et al. Patient and carer preferences for home support services in early stage dementia. Ageing Mental Health. 2016; 22: 270-79.

10- Van der Roest HG, Wenborn J, Pastink C, Dröes R-M, Orrell M. Assistive technology for memory support in dementia. Cochrane Database Syst Rev 2017; 6:CD009627-CD. https://doi.org/10.1002/14651858.CD009627.pub2

11- Ownby RL, Hertzog C, Czaja SJ. Tailored information and automated reminding to improve medication adherence in Spanish- and English-speaking elders treated for memory impairment. Clinical Gerontologist 2012;35(3):221-38.

12- Gathercole R, Bradley R, Harper E, et al. Assistive technology and telecare to maintain independent living at home for people with dementia: the ATTILA RCT.

13- Lauriks S, Reinersmann A, Van der Roest HG, et al. Review of ICT-based services for identified unmet needs in people with dementia. Ageing research reviews 2007; 6:22346. 
14- McGrath, M, Passmore, P. Home-based memory rehabilitation programme for persons with mild dementia. Ir J Med Sci 2009; 178 (suppl 8); S330.

15- Topo P. Technology studies to meet the needs of people with dementia and their caregivers: a literature review. Journal of Applied Gerontology 2008; 28:5-37.

16- Meiland F, Innes A, Mountain G, et al. Technologies to support community-dwelling persons with dementia: a position paper on issues regarding development, usability, effectiveness and cost-effectiveness, deployment, and ethics. JMIR Rehabil Assist Technol 2017; 4(1):e1.

17- Gibson G, Newton L, Pritchard G, Finch T, Brittain K, Robinson L. The provision of assistive technology products and services for people with dementia in the United Kingdom. Dementia 2016; 15:681-701.

18- Cahill S, Macijauskiene J, Nygård A-M, Faulkner J-P, Hagen I. Technology in dementia care. Technology and Disability 2007;19(2):55-60.

19- Chester H, Beresford R, Clarkson P, et al. The Dementia Early Stage Cognitive Aids New Trial (DESCANT) intervention: A goal attainment scaling approach to promote selfmanagement. Int J Geriatr Psychiatry 2021 May;36(5):784-793. doi: 10.1002/gps.5479. Epub 2020 Dec 15.

20- Ministerial Advisory Group on Dementia Research. Final report from the MAGDR subgroup 1 on priority topics in dementia research. MRC, 2011.

21- Chester H, Clarkson P, Davies L, et al. Cognitive aids for people with early stage dementia versus treatment as usual (Dementia Early Stage Cognitive Aids New Trial (DESCANT)): study protocol for a randomised controlled trial. Trials 2018; 19:546, https://doi.org/10.1186/s13063-018-2933-8

22- Chester $\mathrm{H}$, Beresford $\mathrm{R}$, Clarkson $\mathrm{P}$, et al. Implementing the Dementia Early Stage Cognitive Aids New Trial (DESCANT) intervention: mixed-method process evaluation alongside a pragmatic randomised trial. Aging Mental Health 2020; 1-13.

23- Bucks RS, Ashworth DL, Wilcock GK, Siegfried K. Assessment of activities of daily living in dementia: development of the Bristol Activities of Daily Living Scale. Age Ageing 1996; 25:113-20.

24- Hyde M, Wiggins RD, Higgs P, Blane DB. A measure of quality of life in early old age: The theory, development and properties of a needs satisfaction model (CASP-19). Aging Mental Health 2003; 7:186-94.

25- Hughes CP, Berg L, Danziger WL, Coben LA, Martin RL. A new clinical scale for the staging of dementia. Br J Psychiatry 1982; 140: 566-72.

26- Smith SC, Lamping DL, Banerjee S, et al. Measurement of health related quality of life for people with dementia: development of a new instrument (DEMQOL) and an evaluation of current methodology. Health Technol Assess 2005; 9:10.

27- Coast J, Flynn TN, Natarajan L, Valuing the ICECAP capability index for older people. Soc Sci Med 2008; 67: 874-82.

28- Lubben J, Gironda M. Centrality of social ties to the health and well-being of older adults. In: Berkman B, Harooytan L, (eds). Social work and health care in an aging world. Springer, 2003; 319-50.

29- Giebel CM, Challis D, Montaldi D. A revised interview for Deterioration in Daily activities in Dementia (R-IDDD) reveals the relationship between social activities and well-being. Dementia 2016; 15:1068-81.

30- Molloy D, Standish T. Mental status and neuropsychological assessment: a guide to the Standardised Mini-Mental State Examination. Int Psychogeriatr 1997; 9: 87-94.

31- Beecham J, Knapp M. Costing psychiatric interventions. In: Thornicroft G, Brewin CR, Wing J, (eds). Measuring mental health needs. Gaskell, 1992.

32- Wimo A, Wetterholm AL, Mastey V, Winblad B. Evaluation of the healthcare utilisation and caregiver time in anti-dementia drug trials - a quantitative battery. In: Wimo A, Jonsson B, Karlsson G, Winblad B, (eds). Health economics of dementia. Wiley, 1998. 
33- Abendstern M, Davies K, Poland F. et al. Reflecting on the research encounter for people in the early stages of dementia: Lessons from an embedded qualitative study. Dementia 2019; doi: 10.1177/1471301219855295.

34- Goldberg DP. Manual of the General Health Questionnaire. NFER-Nelson, 1978.

35- Vernooji-Dassen M, Felling A, Brummelkamp E, Dauzenberg M, van den Bos G, Grol R. Assessment of caregiver's competence in dealing with the burden of caregiving for a dementia patient: a short sense of competence questionnaire (SSCQ) suitable for clinical practice. J Am Geriatr Soc 1997; 47:256-7.

36- Russell D, Hoare ZSJ, Whitaker R, Whitaker CJ, Russell IT. Generalised method for adaptive randomisation in clinical trials. Stat Med 2011; 30:922-34.

37- Clarkson P, Venables D, Hughes J, Burns A, Challis D. Integrated specialist assessment of older people and predictors of care-home admission. Psychological Medicine 2006; 36: 1011-1021.

38- Detry MA, Ma Y. Analyzing repeated measurements using mixed models. JAMA 2016; 315:407-8.

39- Charlesworth G, Burnell K, Hoe J, Orrell M, Russell I. Acceptance checklist for clinical effectiveness pilot trials: a systematic approach. BMC Medical Research Methodology 2013; $13: 78$.

40- Clarkson P, Challis D, Hughes J, Roe B, Davies L, Russell I, et al. Components, impacts and costs of dementia home support: a research programme including the DESCANT RCT. Programme Grants Appl Res 2021;9(6)

41- Greenaway MC, Duncan NL, Smith GE. The memory support system for mild cognitive impairment: Randomized trial of a cognitive rehabilitation intervention. Int J Geriatr Psychiatry 2012; 28:402-09.

42- Clare L, Linden DEJ, Woods RT, et al. Goal-oriented cognitive rehabilitation for people with early-stage Alzheimer disease: A single-blind randomized controlled trial of clinical efficacy. Am J Geriatr Psychiatry 2010; 18:928-39.

43- Dewar BK, Kapur N, Kopelman M. Do memory aids help everyday memory? A controlled trial of a memory aids service. Neuropsychological rehabilitation 2018; 28:614-32.

44- Howard R, Phillips $\mathrm{P}$, Johnson $\mathrm{T}$, et al. Determining the minimum clinically important differences for outcomes in the DOMINO trial. Int J Geriatr Psychiatry 2011; 26:812-17.

45- Giebel CM, Sutcliffe C, Challis D. Activities of daily living and quality of life across different stages of dementia: a UK study. Aging Mental Health 2015; 19:63-71.

46- Harding AJE, Morbey H, Ahmed F, et al. A Core Outcome Set for non-pharmacological community based interventions for people living with dementia at home: a systematic review of outcome measurement instruments. Gerontologist 2020; XX:1-14, doi:10.1093/geront/gnaa071. 


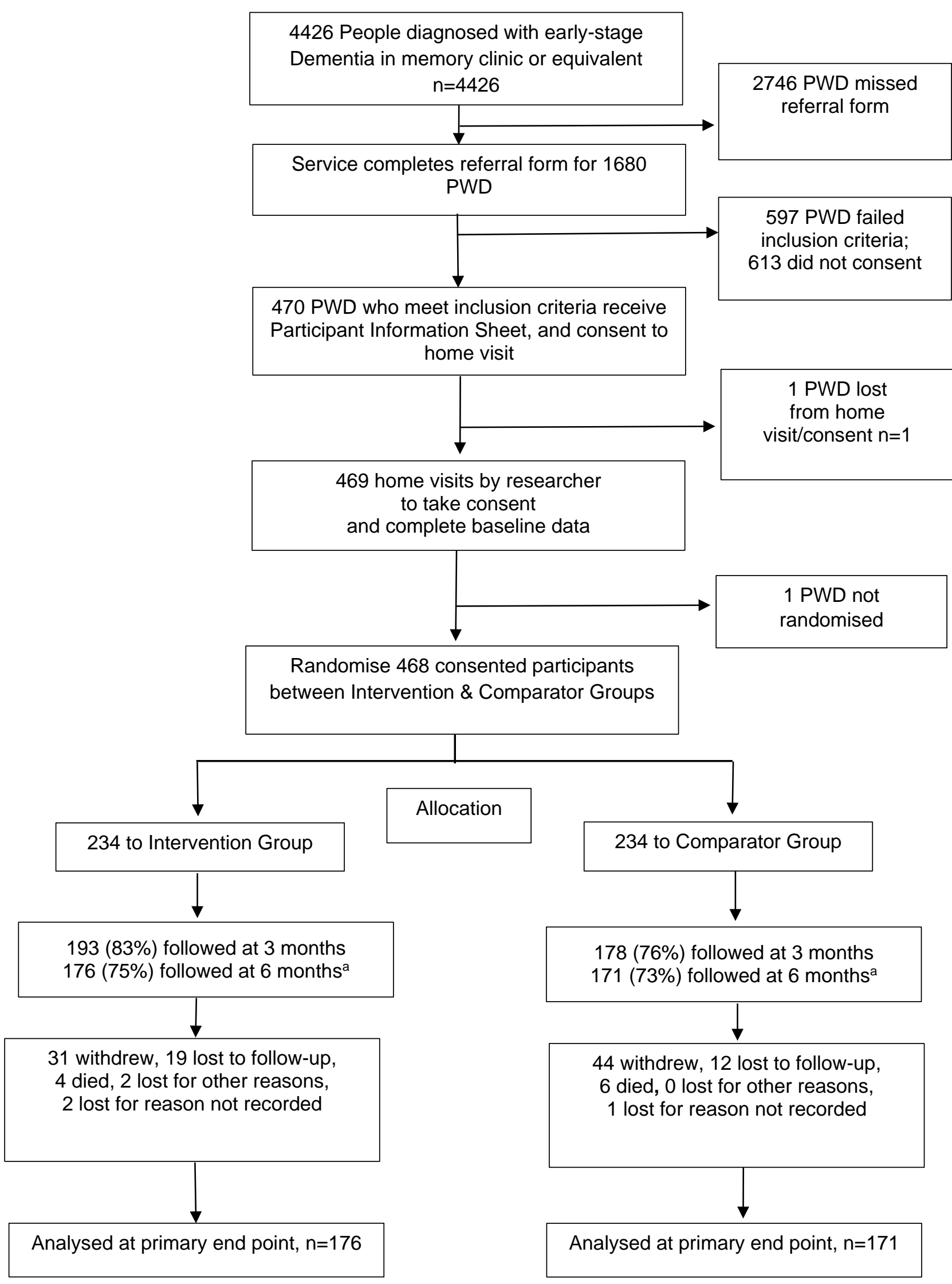

a Though final follow up was originally at 12 months, the DMEC agreed to reduce this to 6 months after the pilot.

Fig 1. Flowchart for participants through the DESCANT trial. PWD = person with dementia 
Table 1 Baseline characteristics of randomised participants (people with dementia) and those providing data for analysis of the primary end point (BADLS score at 6 months) by arm

\begin{tabular}{|c|c|c|c|c|}
\hline & \multicolumn{2}{|c|}{ Randomised sample } & \multicolumn{2}{|c|}{ Sample for primary analysis } \\
\hline & $\begin{array}{l}\text { Intervention } \\
(\mathrm{n}=234)\end{array}$ & $\begin{array}{l}\text { Comparator } \\
(n=234)\end{array}$ & $\begin{array}{l}\text { Intervention } \\
(n=176)\end{array}$ & $\begin{array}{c}\text { Comparator } \\
(n=171)\end{array}$ \\
\hline $\begin{array}{l}\text { Mean }(95 \% \mathrm{Cl}) \text { age (years) } \\
\text { Median } \\
\text { Standard Deviation } \\
\text { Minimum } \\
\text { Maximum } \\
\end{array}$ & $\begin{array}{r}79.6(78.7,80.4) \\
80.0 \\
6.7 \\
60.0 \\
99.0 \\
\end{array}$ & $\begin{array}{r}79.5(78.6,80.4) \\
81.0 \\
7.2 \\
56.0 \\
95.0 \\
\end{array}$ & $\begin{array}{r}79.2 \\
79.0 \\
6.8 \\
60.0 \\
99.0 \\
\end{array}$ & $\begin{array}{r}78.9 \\
80.0 \\
7.2 \\
56.0 \\
93.0 \\
\end{array}$ \\
\hline $\begin{array}{l}\text { Gender: } \\
\text { Male } \\
\text { Female }\end{array}$ & $\begin{array}{l}112(48 \%) \\
122(52 \%)\end{array}$ & $\begin{array}{l}108(46 \%) \\
126(54 \%)\end{array}$ & $\begin{array}{l}88(50.0) \\
88(50.0) \\
\end{array}$ & $\begin{array}{l}85(49.7) \\
86(50.3) \\
\end{array}$ \\
\hline $\begin{array}{l}\text { Ethnicity: } \\
\text { White } \\
\text { Non-White } \\
\end{array}$ & $\begin{array}{r}211(90 \%) \\
23(10 \%) \\
\end{array}$ & $\begin{array}{r}216(92 \%) \\
18 \quad(8 \%) \\
\end{array}$ & $\begin{array}{r}161(91.5) \\
15(8.5) \\
\end{array}$ & $\begin{array}{r}161(94.1) \\
10(5.9) \\
\end{array}$ \\
\hline $\begin{array}{l}\text { Marital Status: } \\
\text { Single } \\
\text { Married or cohabiting } \\
\text { Separated or divorced } \\
\text { Widowed } \\
\text { Missing } \\
\end{array}$ & $\begin{array}{c}10(4 \%) \\
152(65 \%) \\
9(4 \%) \\
62(26 \%) \\
1(0.4 \%) \\
\end{array}$ & $\begin{array}{r}4(2 \%) \\
150(64 \%) \\
18(7 \%) \\
62(27 \%) \\
0 \\
\end{array}$ & $\begin{array}{r}5(2.8) \\
123(69.9) \\
8(4.6) \\
39(22.2) \\
1(0.6) \\
\end{array}$ & $\begin{array}{r}2(1.2) \\
120(70.2) \\
10(5.9) \\
39(22.8) \\
0 \\
\end{array}$ \\
\hline $\begin{array}{l}\text { Usually living: } \\
\text { Own home with partner } \\
\text { Own home with carer } \\
\text { Own home alone } \\
\text { Supported accommodation } \\
\text { Other }\end{array}$ & $\begin{array}{r}148(63 \%) \\
12(5 \%) \\
60(26 \%) \\
7(3 \%) \\
7(3 \%) \\
\end{array}$ & $\begin{array}{r}144(61 \%) \\
13(6 \%) \\
61(26 \%) \\
6(3 \%) \\
10(4 \%) \\
\end{array}$ & $\begin{array}{r}120(68.2) \\
9(5.1) \\
36(20.5) \\
6(3.4) \\
5(2.8) \\
\end{array}$ & $\begin{array}{r}119(69.6) \\
8(4.7) \\
35(20.5) \\
4(2.3) \\
5(2.9) \\
\end{array}$ \\
\hline $\begin{array}{l}\text { Accommodation Types } \\
\text { Owner occupied } \\
\text { Privately rented } \\
\text { Rented from local authority or } \\
\text { housing association } \\
\text { Other }\end{array}$ & $\begin{array}{r}195(83 \%) \\
13(6 \%) \\
23(10 \%) \\
3(1 \%)\end{array}$ & $\begin{array}{c}199(85 \%) \\
9(4 \%) \\
23(10 \%) \\
3(1 \%)\end{array}$ & $\begin{array}{r}142(80.7) \\
11(6.3) \\
20(11.4) \\
3(1.7) \\
\end{array}$ & $\begin{array}{r}150(87.7) \\
6(3.5) \\
12(7.0) \\
3(1.8) \\
\end{array}$ \\
\hline $\begin{array}{l}\text { Living with Primary Carer } \\
\text { Not living with Primary Carer }\end{array}$ & $\begin{array}{r}147(63 \%) \\
87(37 \%) \\
\end{array}$ & $\begin{array}{r}148(63 \%) \\
86(37 \%) \\
\end{array}$ & $\begin{array}{r}120(68.2) \\
56(31.8) \\
\end{array}$ & $\begin{array}{r}122(71.4) \\
49(28.6) \\
\end{array}$ \\
\hline $\begin{array}{l}<0 \text { days since } 1 \text { st Memory } \\
\text { Clinic } \\
\geq 90 \text { days since } 1 \text { st Memory } \\
\text { Clinic }\end{array}$ & $\begin{array}{r}61(26 \%) \\
173(74 \%)\end{array}$ & $\begin{array}{r}58(25 \%) \\
176(75 \%)\end{array}$ & $\begin{array}{r}47(26.7) \\
129(73.3)\end{array}$ & $\begin{array}{r}40(23.4) \\
131(76.6)\end{array}$ \\
\hline Male carer N (\%) & $73(31.2)$ & $73(31.2)$ & $58(33.92)$ & $62(35.2)$ \\
\hline Mean (SD) carer age (years) & $65.9(13.22)$ & $66.3(13.44)$ & $68.1(12.93)$ & $67.2(13.08)$ \\
\hline Mean (SD) BADLS score & $12.12(8.8)$ & $11.5(8.5)$ & $11.98(9.0)$ & $10.04(7.5)$ \\
\hline Mean (SD) S-MMSE score & $22.38(5.1)$ & $22.6(4.7)$ & $22.5(5.0)$ & $22.8(4.6)$ \\
\hline
\end{tabular}


Table 2 Unadjusted findings for BADLS (primary outcome) by arm

\begin{tabular}{|c|c|c|c|c|c|}
\hline Time points & Intervention & Comparator & Total & $\begin{array}{c}\text { Mean } \\
\text { Difference }^{a} \\
(95 \% \mathrm{Cl})\end{array}$ & p \\
\hline $\begin{array}{l}\text { Baseline } \\
\mathrm{n} \\
\text { Mean (95\% Cl) } \\
\text { Median } \\
\text { SD } \\
\text { Missing (\%) } \\
\end{array}$ & $\begin{array}{r}234 \\
12.1(10.9,13.3) \\
11.0 \\
8.8 \\
0 \\
\end{array}$ & $\begin{array}{r}234 \\
11.5(10.4,12.6) \\
9.0 \\
8.5 \\
0 \\
\end{array}$ & $\begin{array}{r}468 \\
11.8(11.03,12.6) \\
10.0 \\
8.7 \\
0 \\
\end{array}$ & $0.61(-0.96,2.19)$ & 0.4 \\
\hline $\begin{array}{l}3 \text { Months } \\
\mathrm{n} \\
\text { Mean }(95 \% \mathrm{Cl}) \\
\text { Median } \\
\text { SD } \\
\text { Missing (\%) } \\
\end{array}$ & $\begin{array}{r}193 \\
12.1(10.9,13.4) \\
10.0 \\
8.9 \\
41(17.5)\end{array}$ & $\begin{array}{r}178 \\
11.6(10.1,12.9) \\
10.0 \\
9.7 \\
56(23.9) \\
\end{array}$ & $\begin{array}{r}371 \\
11.9(10.9,12.8) \\
10.0 \\
9.3 \\
98(20.9) \\
\end{array}$ & $0.64(-1.3,2.5)$ & 0.5 \\
\hline $\begin{array}{l}6 \text { Months } \\
\mathrm{n} \\
\text { Mean }(95 \% \mathrm{Cl}) \\
\text { Median } \\
\text { SD } \\
\text { Missing (\%) }\end{array}$ & $\begin{array}{r}176 \\
14.6(13.1,16.2) \\
12.5 \\
10.4 \\
58(24.8)\end{array}$ & $\begin{array}{r}171 \\
12.6(11.4,13.8) \\
12.0 \\
8.1 \\
63(26.9)\end{array}$ & $\begin{array}{r}347 \\
13.6(12.6,14.6) \\
12.0 \\
9.3 \\
121(25.9)\end{array}$ & $2.02(0.06,3.9)$ & 0.05 \\
\hline
\end{tabular}

$\mathrm{SD}=$ Standard deviation, $\mathrm{Cl}=$ Confidence Interval;

Bristol Activities of Daily Living Scale (BADLS): scores from 0 to 60; higher scores show greater dependence.

BADLS Score: ranges 0 (totally independent) to 60(totally dependent); higher scores indicates greater dependency

a Mean Difference is based on Intervention-Comparator 




Here N's are: 468,371 and 347 for the three time points respectively

Fig 2 Mean $(95 \% \mathrm{CI})$ BADLS Scores (adjusted) over time by group allocated 
Table 3 Adjusted (multi-level mixed model) estimates for primary outcome, BADLS: coefficients

\begin{tabular}{|c|c|c|c|c|c|}
\hline Parameters & $\begin{array}{l}\text { Reference } \\
\text { Category }\end{array}$ & $\begin{array}{l}\text { Coefficient } \\
\text { (B) }\end{array}$ & $95 \% \mathrm{Cl}(\mathrm{B})$ & 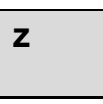 & p-value \\
\hline$\frac{\text { Treatment arm: }}{\text { Intervention }}$ & Comparator & 0.70 & $-0.94,2.34$ & 0.84 & 0.40 \\
\hline $\begin{array}{l}\text { Age categories } \\
\leq 70 \\
71-75 \\
76-80 \\
86-90 \\
90+\end{array}$ & 81-85 years & $\begin{array}{r}-0.54 \\
-2.29 \\
-2.56 \\
-0.14 \\
6.76\end{array}$ & $\begin{array}{l}-3.32,2.23 \\
-4.68,0.10 \\
-4.64,-0.47 \\
-2.56,2.28 \\
2.55,10.97\end{array}$ & $\begin{array}{r}-0.38 \\
-1.88 \\
-2.40 \\
-0.11 \\
3.15 \\
\end{array}$ & $\begin{array}{c}0.70 \\
0.06 \\
0.02^{*} \\
0.91 \\
0.00^{\star}\end{array}$ \\
\hline Gender (Female) & Male & -0.18 & $-1.77,1.41$ & -0.22 & 0.83 \\
\hline Ethnicity (Non-White) & White & 3.50 & $0.64,6.38$ & 2.40 & $0.02^{*}$ \\
\hline $\begin{array}{l}\geq 90 \text { days since } 1 \text { st } \\
\text { attended Memory Clinic }\end{array}$ & $<90$ days & -0.95 & $-2.76,0.87$ & -1.02 & 0.31 \\
\hline Living with Primary Carer & No & 0.49 & $-1.25,2.22$ & 0.55 & 0.58 \\
\hline
\end{tabular}

${ }^{*} \mathrm{p}<0.05$

Bristol Activities of Daily Living Scale (BADLS): scores from 0 to 60; higher scores show greater dependence. Intraclass Correlation Coefficient (ICC) for 'Trust' $=0.01$

We fitted a multi-level mixed-effect model with all the above covariates as fixed-effect and intercept as random effect.

We treated participants as Level 1 and 'Trusts' as Level 2. 
Table 4 Adjusted (multi-level mixed model) estimates for secondary outcomes: coefficients

\begin{tabular}{l|r|r|r|r}
\hline \multicolumn{1}{c|}{ Outcomes $^{{ }^{1}}$} & Coefficient (B) & 95\% Cl (B) & \multicolumn{1}{c|}{ z } & p-value \\
\hline CASP19 $^{2}$ & -0.04 & $-1.40,1.32$ & -0.06 & 0.95 \\
\hline CASP19 & -0.07 & $-1.42,1.28$ & -0.10 & 0.92 \\
\hline CDR & -0.14 & $-0.82,0.53$ & -0.43 & 0.67 \\
\hline DEMQOL & 0.13 & $-2.29,2.55$ & 0.11 & 0.92 \\
\hline LSNS-R & -0.89 & $-2.71,0.92$ & -0.96 & 0.34 \\
\hline RIDDD Initiative & 0.89 & $-2.03,3.82$ & 0.60 & 0.55 \\
\hline RIDDD Performance & -0.77 & $-3.66,2.11$ & -0.53 & 0.60 \\
\hline S-MMSE & -0.20 & $-1.08,0.68$ & -0.45 & 0.70 \\
\hline GHQ-12 & -0.38 & $-1.32,0.55$ & -0.81 & 0.42 \\
\hline SSCQ & -0.43 & $-1.46,0.59$ & -0.83 & 0.40 \\
\hline
\end{tabular}

\section{${ }^{*} \mathrm{p}<0.05$}

Ns respectively for T1; T2; T3 are: CASP 19a $(451 ; 358 ; 322)$; CASP 19b $(467 ; 365 ; 342)$; CDR $(466 ; 370 ; 347$; DEMQOL (446; 350; 323; LSNS-R (468; 369; 346); RIDDD Initiative (465; 365; 342); RIDDD Performance (466; 368; 343); S-MMSE (466; 367; 340); GHQ-12 (468; 369; 344); SSCQ (468; 368; 343).

${ }^{1}$ Estimates are for treatment arm with the comparator group as the reference category ${ }^{2}$ CASP19 by the patients

${ }^{3}$ CASP19 by the Carer

Intraclass Correlation Coefficient (ICC) for 'Trust' = CASP19²(0.000), CASP19³ (0.003), CDR(0.02), DEMQOL (0.000), LSNS-R(0.000), RIDDD Initiative(0.03), RIDDD performance(0.000), S-MMSE (0.03), GHQ-

12(0.000), and SSCQ(0.007)

We fitted a multi-level mixed-effect model with the variables: age, gender, ethnicity, time since $1^{\text {st }}$ attendance at memory clinic and whether living with carer as fixed-effect covariates.

We treated participants as Level 1 and 'Trusts' as Level 2.

\section{APPENDIX: Supplementary (online) tables}


Table A1 Number (\%) of participants using services: comparison of the Treatment as Usual and intervention groups

\begin{tabular}{|c|c|c|c|c|c|c|}
\hline \multirow[t]{2}{*}{ Service used } & \multicolumn{3}{|c|}{ Baseline period $^{1}$} & \multicolumn{3}{|c|}{ Follow-up period ${ }^{2}$} \\
\hline & $\begin{array}{c}\text { TAU } \\
(\mathrm{N}=234)\end{array}$ & $\begin{array}{c}\text { Intervention } \\
(\mathrm{N}=234)\end{array}$ & $P^{*}$ & $\begin{array}{c}\text { TAU } \\
(\mathrm{N}=229)\end{array}$ & $\begin{array}{c}\text { Intervention } \\
(\mathrm{N}=226)\end{array}$ & $\mathbf{P *}^{*}$ \\
\hline Home care worker & $35(15.0)$ & $40(17.1)$ & 0.61 & $35(15.3)$ & $40(17.7)$ & 0.53 \\
\hline Case/care Manager & $13(5.6)$ & $9(3.8)$ & 0.51 & $12(5.3)$ & $4(9.0)$ & 0.66 \\
\hline Social Worker & $22(9.4)$ & $21(9.0)$ & 1.00 & $8(3.5)$ & $18(8.0)$ & $0.05^{\star}$ \\
\hline Dementia Adviser worker & $48(20.5)$ & $32(13.7)$ & 0.07 & $24(10.5)$ & $26(11.5)$ & 0.77 \\
\hline Dementia support worker & $39(16.7)$ & 42(17.9) & 0.81 & $26(11.4)$ & $39(17.3)$ & 0.08 \\
\hline Support worker & $16(6.8)$ & $13(5.6)$ & 0.70 & $17(7.4)$ & $20(8.8)$ & 0.61 \\
\hline Voluntary worker & $48(20.5)$ & $53(22.6)$ & 0.65 & $60(26.3)$ & $52(23.0)$ & 0.45 \\
\hline $\begin{array}{l}\text { Community Mental Health } \\
\text { Nurse }\end{array}$ & $61(26.1)$ & $60(25.6)$ & 1.00 & $25(10.9)$ & $28(12.4)$ & 0.66 \\
\hline Community District Nurse & $29(12.4)$ & $31(13.2)$ & 0.89 & $30(13.1)$ & $24(10.6)$ & 0.47 \\
\hline GP & $178(76.1)$ & $178(76.1)$ & 1.00 & $156(68.1)$ & $168(74.3)$ & 0.15 \\
\hline GP Practice Nurse & $109(46.6)$ & 114(48.7) & 0.71 & $125(54.6)$ & $122(54.0)$ & 0.93 \\
\hline Community Pharmacist & $66(28.2)$ & $61(26.1)$ & 0.68 & $82(35.8)$ & $97(42.9)$ & 0.13 \\
\hline Psychologist & 12(5.1) & $8(3.4)$ & 0.49 & $11(4.8)$ & $13(5.8)$ & 0.40 \\
\hline Physiotherapist & $33(14.1)$ & $25(10.7)$ & 0.33 & $37(16.2)$ & $34(15.0)$ & 0.80 \\
\hline Dietician & $7(3.0)$ & $3(1.3)$ & 0.34 & $3(1.3)$ & $5(2.2)$ & 0.36 \\
\hline Health visitor & $0(0.0)$ & $1(0.4)$ & 1.00 & $0(0.0)$ & $4(1.8)$ & 0.06 \\
\hline Chiropodist & $69(29.5)$ & $76(32.5)$ & 0.55 & $73(31.9)$ & $87(38.5)$ & 0.14 \\
\hline Benefits Adviser & $13(5.6)$ & $10(4.3)$ & 0.67 & $21(9.2)$ & $15(6.6)$ & 0.39 \\
\hline Short-term respite care & $1(0.4)$ & $1(0.4)$ & 1.00 & $3(1.3)$ & $4(1.8)$ & 0.72 \\
\hline Transport & $15(6.4)$ & $18(7.7)$ & 0.72 & $18(7.9)$ & $22(9.7)$ & 0.51 \\
\hline Drop-in centre & $17(7.3)$ & $10(4.3)$ & 0.23 & $15(6.6)$ & $16(7.1)$ & 0.85 \\
\hline Day care centre & $10(4.3)$ & $10(4.3)$ & 1.00 & $0(0.0)$ & $1(0.4)$ & 0.50 \\
\hline All out-patient visits & $164(70.1)$ & $167(71.4)$ & 0.84 & $145(63.3)$ & $151(66.8)$ & 0.49 \\
\hline All in patient visits & $22(9.4)$ & $36(15.4)$ & 0.07 & $29(12.6)$ & $38(16.7)$ & 0.24 \\
\hline In-patient: AE visit & $16(6.8)$ & $16(6.8)$ & 1.00 & $10(4.4)$ & $16(7.1)$ & 0.23 \\
\hline $\begin{array}{l}\text { In-patient - General } \\
\text { Medical Ward }\end{array}$ & $7(3.0)$ & $21(9.0)$ & $0.01^{*}$ & $10(4.4)$ & $21(9.3)$ & $0.03^{*}$ \\
\hline In-patient - Geriatric Ward & $0(0.0)$ & $3(1.3)$ & 0.25 & $4(1.7)$ & $0(0.0)$ & 0.12 \\
\hline In-patient - Surgical Ward & $5(2.1)$ & $8(3.4)$ & 0.58 & $12(5.2)$ & $12(5.3)$ & 1.00 \\
\hline All aids and adaptations & $148(63.2)$ & $151(64.5)$ & 0.85 & $106(46.3)$ & $61(27.0)$ & $0.00^{*}$ \\
\hline Adaptations & $32(13.7)$ & $32(13.7)$ & 1.00 & $10(4.4)$ & $17(7.5)$ & 0.17 \\
\hline Equipment & $125(53.4)$ & $131(56.0)$ & 0.64 & $101(44.1)$ & $49(21.7)$ & $0.00^{\star}$ \\
\hline Technological aids & $60(26.5)$ & $59(25.5)$ & 1.00 & $47(20.5)$ & $9(4.0)$ & $0.00^{\star}$ \\
\hline Memory aid: clock ${ }^{a}$ & $44(18.8)$ & $45(19.2)$ & 1.00 & $61(26.6)$ & $2(0.9)$ & $0.00^{*}$ \\
\hline $\begin{array}{l}\text { Memory aid: Medication } \\
\text { reminder }\end{array}$ & $81(34.6)$ & $75(32.1)$ & 0.62 & $89(38.9)$ & $0(0.0)$ & $0.00^{*}$ \\
\hline
\end{tabular}

At each interviewed time point (T1, T2, T3) details of services used over the preceding 3 months were elicited.

${ }^{1}$ Baseline (T1); ${ }^{2}$ Follow up (T2 and T3).

${ }^{*} p<0.05$, chi-square test

a Memory aids already received or held by participants in each group; intervention group also received the

DESCANT intervention comprising package of memory aids and visits by a Dementia Support Practitioner at baseline.

Tables A2-A11 - full model data for each secondary outcome 
Table A2 full model data for the secondary outcome: CASP 19 (by the patients) coefficients

\begin{tabular}{|c|c|c|c|c|c|}
\hline Parameters & $\begin{array}{l}\text { Reference } \\
\text { Category }\end{array}$ & $\begin{array}{l}\text { Coefficient } \\
\text { (B) }\end{array}$ & $95 \% \mathrm{Cl}(\mathrm{B})$ & $\mathbf{z}$ & p-value \\
\hline$\frac{\text { Treatment arm: }}{\text { Intervention }}$ & Comparator & -0.04 & $-1.40,1.32$ & -0.06 & 0.95 \\
\hline $\begin{array}{l}\text { Age categories } \\
\leq 70 \\
71-75 \\
76-80 \\
86-90 \\
90+ \\
\end{array}$ & 81-85 years & $\begin{array}{r}1.02 \\
2.58 \\
1.70 \\
-0.33 \\
1.46 \\
\end{array}$ & $\begin{array}{r}-1.22,3.27 \\
0.64,4.52 \\
0.01,3.39 \\
-2.29,1.64 \\
-1.94,4.86 \\
\end{array}$ & $\begin{array}{r}0.89 \\
2.61 \\
1.97 \\
-0.33 \\
0.84 \\
\end{array}$ & $\begin{array}{c}0.37 \\
0.01^{*} \\
0.05 \\
0.75 \\
0.40 \\
\end{array}$ \\
\hline Gender (Female) & Male & 1.35 & $0.05,2.64$ & 2.05 & $0.04^{*}$ \\
\hline Ethnicity (Non-White) & White & -0.60 & $-2.89,1.68$ & -0.52 & 0.61 \\
\hline $\begin{array}{l}\geq 90 \text { days since } 1 \mathrm{st} \\
\text { attended Memory Clinic }\end{array}$ & $<90$ days & 0.16 & $-1.30,1.62$ & 0.21 & 0.83 \\
\hline Living with Primary Carer & No & 0.64 & $-0.74,2.02$ & 0.91 & 0.36 \\
\hline
\end{tabular}

${ }^{*} \mathrm{p}<0.05$

CASP19 score varies from 0 to 57 ; higher scores indicate better QoL.

Intraclass Correlation Coefficient (ICC) for 'Trust' = 0

We fitted a multi-level mixed-effect model with the covariates in this table as fixed effect and intercept as random effects. We treated participants as Level 1 and 'Trusts' as Level 2.

Table A3 full model data for the secondary outcome: CASP19 (by the carer) coefficients

\begin{tabular}{l|l|c|c|c|c}
\hline Parameters & \multicolumn{1}{|c|}{$\begin{array}{c}\text { Reference } \\
\text { Category }\end{array}$} & $\begin{array}{c}\text { Coefficient } \\
\text { (B) }\end{array}$ & $\mathbf{9 5 \% ~ C l ~ ( B ) ~}$ & $\mathbf{z}$-value \\
\hline $\begin{array}{l}\text { Treatment arm: } \\
\text { Intervention }\end{array}$ & Comparator & -0.07 & $-1.42,1.28$ & -0.10 & 0.92 \\
\hline Age categories & $81-85$ years & 0.66 & $-1.58,2.90$ & 0.58 & 0.56 \\
\hline $\mathbf{7 1 0}$ & & 0.94 & $-0.99,2.88$ & 0.96 & 0.34 \\
$76-80$ & & 0.29 & $-1.39,1.98$ & 0.34 & 0.74 \\
$86-90$ & & 0.04 & $-1.99,1.92$ & -0.04 & 0.97 \\
$90+$ & & 0.66 & $-4.07,2.76$ & -0.38 & 0.71 \\
\hline Gender (Female) & Male & 0.90 & $-0.39,2.19$ & 1.38 & 0.17 \\
\hline Ethnicity (Non-White) & White & -0.57 & $-2.86,1.72$ & 0.50 & 0.62 \\
\hline$\geq 90$ days since 1st & $<90$ days & 0.10 & $-1.35,1.54$ & 0.13 & 0.90 \\
attended Memory Clinic & & & & & $0.00^{\star}$ \\
\hline Living with Primary Carer & No & -3.74 & $-5.13,2.36$ & -5.30 & 0 \\
\hline
\end{tabular}

* $\mathrm{p}<0.05$

CASP19 score varies from 0 to 57 ; higher scores indicate better QoL.

Intraclass Correlation Coefficient (ICC) for 'Trust' $=0.004$

We fitted a multi-level mixed-effect model with the covariates in this table as fixed effect and intercept as random effects. We treated participants as Level 1 and 'Trusts' as Level 2. 
Table A4 full model data for the secondary outcome: CDR coefficients

\begin{tabular}{|c|c|c|c|c|c|}
\hline Parameters & $\begin{array}{l}\text { Reference } \\
\text { Category }\end{array}$ & $\begin{array}{l}\text { Coefficient } \\
\text { (B) }\end{array}$ & $95 \% \mathrm{Cl}(\mathrm{B})$ & $\mathbf{z}$ & p-value \\
\hline$\frac{\text { Treatment arm: }}{\text { Intervention }}$ & Comparator & -0.15 & $-0.82,0.52$ & -0.43 & 0.67 \\
\hline $\begin{array}{l}\text { Age categories } \\
\leq 70 \\
71-75 \\
76-80 \\
86-90 \\
90+\end{array}$ & $81-85$ years & $\begin{array}{r}-0.14 \\
-0.62 \\
0.20 \\
-0.84 \\
-0.18\end{array}$ & $\begin{array}{r}-1.02,0.74 \\
-1.38,0.15 \\
-0.46,0.87 \\
-1.62,-0.06 \\
-1.56,1.19\end{array}$ & $\begin{array}{r}-0.32 \\
-1.57 \\
0.60 \\
-2.12 \\
-0.26\end{array}$ & $\begin{array}{r}0.75 \\
0.12 \\
0.55 \\
0.03^{\star} \\
0.80\end{array}$ \\
\hline Gender (Female) & Male & -0.32 & $-0.83,0.19$ & -1.24 & 0.22 \\
\hline Ethnicity (Non-White) & White & 0.57 & $-0.37,1.51$ & 1.20 & 0.23 \\
\hline $\begin{array}{l}\geq 90 \text { days since } 1 \text { st } \\
\text { attended Memory Clinic }\end{array}$ & $<90$ days & 0.45 & $-0.13,1.03$ & 1.53 & 0.13 \\
\hline Living with Primary Carer & No & -0.06 & $-.062,0.50$ & 0.20 & 0.84 \\
\hline
\end{tabular}

${ }^{*} \mathrm{p}<0.05$

CDR scores from 0 to 30 ; higher is worse or more severe dementia.

Intraclass Correlation Coefficient (ICC) for 'Trust' $=0.02$

We fitted a multi-level mixed-effect model with the covariates in this table as fixed effect and intercept as random effects. We treated participants as Level 1 and 'Trusts' as Level 2.

Table A5 full model data for the secondary outcome: DEMQOL coefficients

\begin{tabular}{|c|c|c|c|c|c|}
\hline Parameters & $\begin{array}{l}\text { Reference } \\
\text { Category }\end{array}$ & $\begin{array}{l}\text { Coefficient } \\
\text { (B) }\end{array}$ & $95 \% \mathrm{Cl}(\mathrm{B})$ & z & p-value \\
\hline $\begin{array}{l}\text { Treatment arm: } \\
\text { Intervention }\end{array}$ & Comparator & 0.13 & $-2.29,2.55$ & 0.11 & 0.92 \\
\hline $\begin{array}{l}\text { Age categories } \\
\leq 70 \\
71-75 \\
76-80 \\
86-90 \\
90+ \\
\end{array}$ & 81-85 years & $\begin{array}{r}-2.72 \\
2.35 \\
1.92 \\
0.62 \\
1.37 \\
\end{array}$ & $\begin{array}{r}-6.76,1.30 \\
-1.14,5.85 \\
1.16,5.00 \\
-2.94,4.18 \\
-4.75,7.50 \\
\end{array}$ & $\begin{array}{r}-1.33 \\
1.32 \\
1.22 \\
0.34 \\
0.44 \\
\end{array}$ & $\begin{array}{l}0.19 \\
0.20 \\
0.22 \\
0.73 \\
0.66 \\
\end{array}$ \\
\hline Gender (Female) & Male & 2.46 & $0.11,4.80$ & 1.20 & $0.04^{*}$ \\
\hline Ethnicity (Non-White) & White & -5.60 & $-9.88,-1.31$ & 2.18 & $0.01^{*}$ \\
\hline $\begin{array}{l}\geq 90 \text { days since } 1 \text { st } \\
\text { attended Memory Clinic }\end{array}$ & $<90$ days & 0.40 & $-2.25,3.05$ & 1.35 & 0.76 \\
\hline Living with Primary Carer & No & 0.53 & $-1.97,3.04$ & 1.28 & 0.67 \\
\hline
\end{tabular}

${ }^{*} \mathrm{p}<0.05$

DEMQOL score varies from 28 to 112; higher score indicates better health related QoL.

Intraclass Correlation Coefficient (ICC) for 'Trust' $=0$

We fitted a multi-level mixed-effect model with the covariates in this table as fixed effect and intercept as random effects. We treated participants as Level 1 and 'Trusts' as Level 2. 
Table A6 full model data for the secondary outcome: LSNS-R coefficients

\begin{tabular}{|c|c|c|c|c|c|}
\hline Parameters & $\begin{array}{l}\text { Reference } \\
\text { Category }\end{array}$ & $\begin{array}{l}\text { Coefficient } \\
\text { (B) }\end{array}$ & $95 \% \mathrm{Cl}(\mathrm{B})$ & $\mathbf{z}$ & p-value \\
\hline$\frac{\text { Treatment arm: }}{\text { Intervention }}$ & Comparator & -0.89 & $-2.71,0.92$ & -0.96 & 0.34 \\
\hline $\begin{array}{l}\text { Age categories } \\
\leq 70 \\
71-75 \\
76-80 \\
86-90 \\
90+\end{array}$ & $81-85$ years & $\begin{array}{r}4.22 \\
1.05 \\
1.89 \\
-1.89 \\
-1.79\end{array}$ & $\begin{array}{r}1.24,7.20 \\
-1.52,3.62 \\
-0.36,4.13 \\
-4.49,0.72 \\
-6.33,2.75\end{array}$ & $\begin{array}{r}2.78 \\
0.80 \\
1.65 \\
-1.42 \\
-0.77\end{array}$ & $\begin{array}{l}0.01^{*} \\
0.42 \\
0.10 \\
0.16 \\
0.44\end{array}$ \\
\hline Gender (Female) & Male & 0.58 & $-1.12,2.29$ & 0.67 & 0.50 \\
\hline Ethnicity (Non-White) & White & 0.64 & $-2.34,3.63$ & 0.42 & 0.67 \\
\hline $\begin{array}{l}\geq 90 \text { days since } 1 \text { st } \\
\text { attended Memory Clinic }\end{array}$ & $<90$ days & -0.02 & $-1.93,1.89$ & -0.02 & 0.99 \\
\hline Living with Primary Carer & No & 0.88 & $-0.94,2.71$ & 0.95 & 0.34 \\
\hline
\end{tabular}

${ }^{*} \mathrm{p}<0.05$

LSNS_R: scores from 0 to 60 ; higher scores indicates more social engagement.

Intraclass Correlation Coefficient (ICC) for 'Trust' $=0$

We fitted a multi-level mixed-effect model with the covariates in this table as fixed effect and intercept as random effects. We treated participants as Level 1 and 'Trusts' as Level 2.

Table A7 full model data for the secondary outcome: RIDDD Initiative coefficients

\begin{tabular}{|c|c|c|c|c|c|}
\hline Parameters & $\begin{array}{l}\text { Reference } \\
\text { Category }\end{array}$ & $\begin{array}{l}\text { Coefficient } \\
\text { (B) }\end{array}$ & $95 \% \mathrm{Cl}(\mathrm{B})$ & $\mathbf{z}$ & p-value \\
\hline $\begin{array}{l}\text { Treatment arm: } \\
\text { Intervention }\end{array}$ & Comparator & 0.89 & $-2.03,3.82$ & 0.60 & 0.55 \\
\hline $\begin{array}{l}\text { Age categories } \\
\leq 70 \\
71-75 \\
76-80 \\
86-90 \\
90+ \\
\end{array}$ & $81-85$ years & $\begin{array}{r}4.05 \\
5.06 \\
4.08 \\
0.42 \\
-5.90 \\
\end{array}$ & $\begin{array}{r}-0.37,8.47 \\
1.23,8.90 \\
0.75,7.42 \\
-3.46,4.31 \\
-12.72,0.91 \\
\end{array}$ & $\begin{array}{r}1.79 \\
2.59 \\
2.40 \\
0.21 \\
-1.70 \\
\end{array}$ & $\begin{array}{r}0.07 \\
0.01^{\star} \\
0.02^{\star} \\
0.83 \\
0.10 \\
\end{array}$ \\
\hline Gender (Female) & Male & 1.07 & $-1.47,3.61$ & 0.82 & 0.41 \\
\hline Ethnicity (Non-White) & White & -2.22 & $-6.92,2.48$ & -0.92 & 0.36 \\
\hline $\begin{array}{l}\geq 90 \text { days since } 1 \text { st } \\
\text { attended Memory Clinic }\end{array}$ & $<90$ days & -0.84 & $-3.74,2.08$ & -0.56 & 0.57 \\
\hline Living with Primary Carer & No & -1.78 & $-4.61,1.05$ & -1.23 & 0.22 \\
\hline
\end{tabular}

${ }^{*} \mathrm{p}<0.05$

RIDDD initiative: scores from 0 to 60 ; higher scores show better initiative.

Intraclass Correlation Coefficient (ICC) for 'Trust' $=0.03$

We fitted a multi-level mixed-effect model with the covariates in this table as fixed effect and intercept as random effects. We treated participants as Level 1 and 'Trusts' as Level 2. 
Table A8 full model data for the secondary outcome: RIDDD Performance coefficients

\begin{tabular}{|c|c|c|c|c|c|}
\hline Parameters & $\begin{array}{l}\text { Reference } \\
\text { Category }\end{array}$ & $\begin{array}{l}\text { Coefficient } \\
\text { (B) }\end{array}$ & $95 \% \mathrm{Cl}(\mathrm{B})$ & $\mathbf{z}$ & p-value \\
\hline$\frac{\text { Treatment arm: }}{\text { Intervention }}$ & Comparator & -0.78 & $-3.66,2.11$ & -0.53 & 0.60 \\
\hline $\begin{array}{l}\text { Age categories } \\
\leq 70 \\
71-75 \\
76-80 \\
86-90 \\
90+ \\
\end{array}$ & 81-85 years & $\begin{array}{r}1.23 \\
4.15 \\
5.23 \\
-2.35 \\
-11.91 \\
\end{array}$ & $\begin{array}{r}-3.69,6.15 \\
-0.08,8.38 \\
1.53,8.93 \\
-6.64,1.94 \\
-19.36,-4.46 \\
\end{array}$ & $\begin{array}{r}0.49 \\
1.92 \\
2.77 \\
-1.08 \\
-3.13 \\
\end{array}$ & $\begin{array}{r}0.62 \\
0.06 \\
0.01^{\star} \\
0.28 \\
0.00^{\star}\end{array}$ \\
\hline Gender (Female) & Male & 0.47 & $-2.34,3.29$ & 0.33 & 0.74 \\
\hline Ethnicity (Non-White) & White & -3.38 & $-8.30,1.53$ & -1.35 & 0.18 \\
\hline $\begin{array}{l}\geq 90 \text { days since } 1 \mathrm{st} \\
\text { attended Memory Clinic }\end{array}$ & $<90$ days & -0.10 & $-3.24,3.05$ & -0.06 & 0.95 \\
\hline Living with Primary Carer & No & -1.88 & $-4.89,1.12$ & -1.23 & 0.22 \\
\hline
\end{tabular}

${ }^{*} \mathrm{p}<0.05$

RIDDD performance: scores from 0 to 76 ; higher scores indicate better performance.

Intraclass Correlation Coefficient (ICC) for 'Trust' $=0$

We fitted a multi-level mixed-effect model with the covariates in this table as fixed effect and intercept as random effects. We treated participants as Level 1 and 'Trusts' as Level 2.

Table A9 full model data for the secondary outcome: SMMSE coefficients

\begin{tabular}{|c|c|c|c|c|c|}
\hline Parameters & $\begin{array}{l}\text { Reference } \\
\text { Category }\end{array}$ & $\begin{array}{l}\text { Coefficient } \\
\text { (B) }\end{array}$ & $95 \% \mathrm{Cl}(\mathrm{B})$ & $\mathbf{z}$ & p-value \\
\hline $\begin{array}{l}\text { Treatment arm: } \\
\text { Intervention }\end{array}$ & Comparator & -0.20 & $-1.08,0.68$ & -0.45 & 0.60 \\
\hline $\begin{array}{l}\text { Age categories } \\
\leq 70 \\
71-75 \\
76-80 \\
86-90 \\
90+ \\
\end{array}$ & $81-85$ years & $\begin{array}{r}-0.78 \\
-0.26 \\
0.09 \\
-0.80 \\
-2.25 \\
\end{array}$ & $\begin{array}{l}-2.27,0.72 \\
-1.56,1.03 \\
-1.03,1.21 \\
-2.10,0.50 \\
-4.51,0.02 \\
\end{array}$ & $\begin{array}{r}-1.02 \\
-0.40 \\
0.16 \\
-1.21 \\
-1.95 \\
\end{array}$ & $\begin{array}{l}0.31 \\
0.69 \\
0.88 \\
0.23 \\
0.05 \\
\end{array}$ \\
\hline Gender (Female) & Male & 0.26 & $-0.59,1.12$ & 0.61 & 0.55 \\
\hline Ethnicity (Non-White) & White & -3.51 & $-5.07,1.95$ & -4.41 & $0.00^{*}$ \\
\hline $\begin{array}{l}\geq 90 \text { days since } 1 \text { st } \\
\text { attended Memory Clinic }\end{array}$ & $<90$ days & 0.32 & $-0.66,1.30$ & 0.65 & 0.52 \\
\hline Living with Primary Carer & No & -0.71 & $-1.64,0.23$ & -1.48 & 0.14 \\
\hline
\end{tabular}

${ }^{*} \mathrm{p}<0.05$

SMMSE: scores from 0 to 30; higher scores indicate better cognitive condition.

Intraclass Correlation Coefficient (ICC) for 'Trust' $=0.03$

We fitted a multi-level mixed-effect model with the covariates in this table as fixed effect and intercept as random effects. We treated participants as Level 1 and 'Trusts' as Level 2. 
Table A10 full model data for the secondary outcome: GHQ-12 coefficients

\begin{tabular}{l|l|c|c|c|c}
\hline Parameters & \multicolumn{1}{|c|}{$\begin{array}{c}\text { Reference } \\
\text { Category }\end{array}$} & $\begin{array}{c}\text { Coefficient } \\
\text { (B) }\end{array}$ & $\mathbf{9 5 \% ~ C l ~ ( B ) ~}$ & $\mathbf{z}$ & p-value \\
\hline Treatment arm: & Comparator & -0.38 & $-1.32,0.55$ & -0.81 & 0.42 \\
\hline Intervention & & & & & \\
\hline Age categories & S1-85 years & 0.02 & $-1.48,1.53$ & 0.03 & 0.97 \\
$71-75$ & & 0.09 & $-1.21,1.38$ & 0.13 & 0.90 \\
$76-80$ & & -0.57 & $-1.71,0.56$ & -0.99 & 0.32 \\
$86-90$ & & -0.18 & $-1.14,1.50$ & 0.27 & 0.80 \\
$90+$ & & -1.26 & $-2.56,2.05$ & -0.22 & 0.83 \\
\hline Gender (Female) & Male & 0.79 & $-2.27,-0.55$ & -3.21 & $0.001^{*}$ \\
\hline Ethnicity (Non-White) & White & -0.33 & $-1.29,0.64$ & -0.67 & 0.50 \\
\hline$\geq 90$ days since 1st & $<90$ days & & & & \\
attended Memory Clinic & & 0.14 & $-0.78,1.10$ & 0.30 & 0.76 \\
\hline Living with Primary Carer & No & & & &
\end{tabular}

${ }^{*} \mathrm{p}<0.05$

GHQ-12: scores from 0 to 60 ; higher scores indicate better health.

Intraclass Correlation Coefficient (ICC) for 'Trust' $=0$

We fitted a multi-level mixed-effect model with the covariates in this table as fixed effect and intercept as random effects. We treated participants as Level 1 and 'Trusts' as Level 2.

Table A11 full model data for the secondary outcome: SSCQ coefficients

\begin{tabular}{l|l|c|c|c|c}
\hline Parameters & $\begin{array}{c}\text { Reference } \\
\text { Category }\end{array}$ & $\begin{array}{c}\text { Coefficient } \\
\text { (B) }\end{array}$ & 95\% CI (B) & $\mathbf{z}$ & p-value \\
\hline Treatment arm: & Comparator & -0.43 & $-1.46,0.59$ & -0.83 & 0.40 \\
\hline Intervention & & & & & \\
\hline Age categories & 81-85 years & 1.02 & $-0.69,2.73$ & 1.17 & 0.24 \\
710 & & -0.13 & $-1.60,1.34$ & -0.17 & 0.86 \\
$76-80$ & & 0.91 & $-0.38,2.19$ & 1.38 & 0.17 \\
$86-90$ & & 0.49 & $-1.01,1.98$ & 0.64 & 0.52 \\
$90+$ & & 0.20 & $-2.40,2.80$ & 0.15 & 0.88 \\
\hline Gender (Female) & Male & 1.23 & $0.25,2.21$ & 2.46 & $0.01^{*}$ \\
\hline Ethnicity (Non-White) & White & -1.93 & $-3.68,-0.17$ & -2.15 & 0.03 \\
\hline$\geq 90$ days since 1st & $<90$ days & -0.54 & $-1.65,0.57$ & -0.96 & 0.34 \\
attended Memory Clinic & & & & & \\
\hline Living with Primary Carer & No & 0.26 & $-0.80,1.32$ & 0.49 & 0.63 \\
\hline
\end{tabular}

${ }^{*} \mathrm{p}<0.05$

SSCQ: scores from 7 to 35 ; higher scores indicate show greater dependence.

Intraclass Correlation Coefficient (ICC) for 'Trust' $=0.01$

We fitted a multi-level mixed-effect model with the covariates in this table as fixed effect and intercept as random

effects. We treated participants as Level 1 and 'Trusts' as Level 2. 
Table A12 ADJUSTED (Multi-level Mixed Model) estimates for primary outcome, BADLS: Coefficients (after imputation)

\begin{tabular}{|c|c|c|c|c|c|}
\hline Parameters & $\begin{array}{l}\text { Reference } \\
\text { Category }\end{array}$ & $\begin{array}{l}\text { Coefficient } \\
\text { (B) }\end{array}$ & $95 \% \mathrm{Cl}(\mathrm{B})$ & $\mathbf{z}$ & $p$-value \\
\hline $\begin{array}{l}\text { Treatment arm: } \\
\text { Intervention }\end{array}$ & Comparator & 0.70 & $-0.92,2.31$ & 0.85 & 0.40 \\
\hline Age categories & & & & & \\
\hline$\leq 70$ & $81-85$ years & -0.59 & $-3.32,2.15$ & -0.42 & 0.67 \\
\hline $71-75$ & & -2.32 & $-4.67,0.03$ & -1.94 & 0.05 \\
\hline $76-80$ & & -2.46 & $-4.51,-0.42$ & -2.36 & $0.02^{*}$ \\
\hline $86-90$ & & -0.03 & $-2.40,2.34$ & -0.03 & 0,98 \\
\hline $90+$ & & 6.59 & $2.49,10.69$ & 3.15 & $0.002^{*}$ \\
\hline$\overline{\text { Gender (Female) }}$ & Male & 0.23 & $-1.79,1.34$ & -0.28 & 0.78 \\
\hline$\overline{\text { Ethnicity (Non-White) }}$ & White & 3.56 & $0.75,6.36$ & 2.48 & $0.01^{*}$ \\
\hline $\begin{array}{l}\geq 90 \text { days since } 1 \text { st } \\
\text { attended Memory Clinic }\end{array}$ & $<90$ days & -0.92 & $-2.70,0.87$ & -1.01 & 0.31 \\
\hline Living with Primary Carer & No & 0.45 & $-1.25,2.14$ & 0.52 & 0.61 \\
\hline
\end{tabular}

${ }^{\star} \mathrm{p}<0.05$

$\mathrm{N}=468$ at each time point.

Bristol Activities of Daily Living Scale (BADLS): scores from 0 to 60; higher scores show greater dependence. Intraclass Correlation Coefficient (ICC) for 'Trust' $=0.01$

We fitted a multi-level mixed-effect model with the variables in the last 5 rows as fixed-effect covariates.

We treated participants as Level 1 and 'Trusts' as Level 2. 


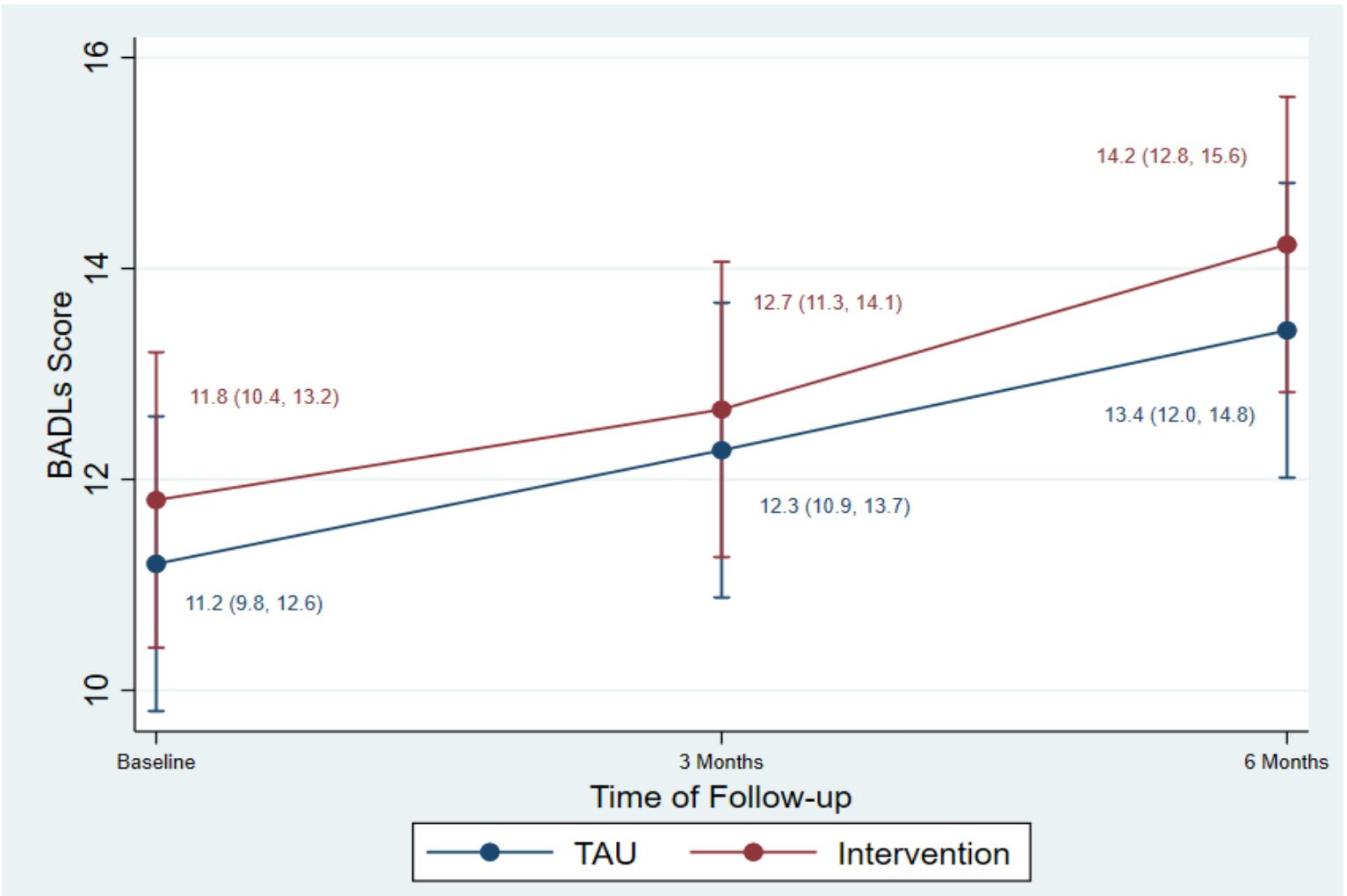

Here N's are 468 for each time point (after multiple imputation).

Figure A1 Mean $(95 \% \mathrm{CI})$ BADLS SCORES over time by randomly assigned group (after imputation) 